\title{
Measurement of four-pane building window filled with a PCM
}

\author{
Martin Kolacek $^{1^{*}}$ \\ ${ }^{1}$ Tomas Bata University in Zlin, Faculty of Applied Informatics, Department of Automation and control Engineering, Nad Stranemi 4511, Zlin, \\ Czech Republic.
}

\begin{abstract}
The transparent building element filled with Phase change materials (PCMs) represent an innovative solution that can achieve thermal comfort in buildings lowering the cooling and heating demand. There are many different PCMs which are used in the building element. Salt hydrates can absorb a large amount of energy and have properties similar to water. Nevertheless, these materials have a tendency to supercool (supercooling effect) and to incongruent melt. This paper reports the results of the measurement specific four-pane window filled with a PMCs. Thermal properties of the window were tested in the climate simulator where the climatic conditions were dynamically controlled. The measurement confirmed high thermal inertia of the window and also reducing heat transfer through the window.
\end{abstract}

\section{Introduction}

There has been an increasing interest in research carried out the thermal energy storage technologies like Phase Change Materials (PCMs). PCMs enhance the energy efficiency of buildings because they can store, release or absorb a large amount of heat or cold in the small temperature range. These materials can stabilize temperature fluctuations and reduce overheating in the room.

PCMs are divided into the different groups depending on the material structure, paraffin, salt hydrates, fatty acids, polyethylene glycols etc. Each material has own advantages and limitations. Paraffin and fatty acids present no supercooling effect, low hysteresis and they are more stable than salt hydrate which can present formation of sediment [1,9].

In recent years PCMs are applied into transparent envelope components. These building components can reduce temperature fluctuation and they are also able to release solar radiation. Additionally [2] investigated experimentally the temperature fluctuation of the interior surface and the heat entered the building, where they used PCM based on paraffin in windows. Salt hydrates are also used in transparent components as describes [3]. The transparent element can absorb visibly and also invisible radiation of the solar radiation spectrum and can convert into heat. The light transmittance of water agrees with the sensitivity curve of the human eye. Due to the fact, PCMs which contain water are selected for transparent building element [4].

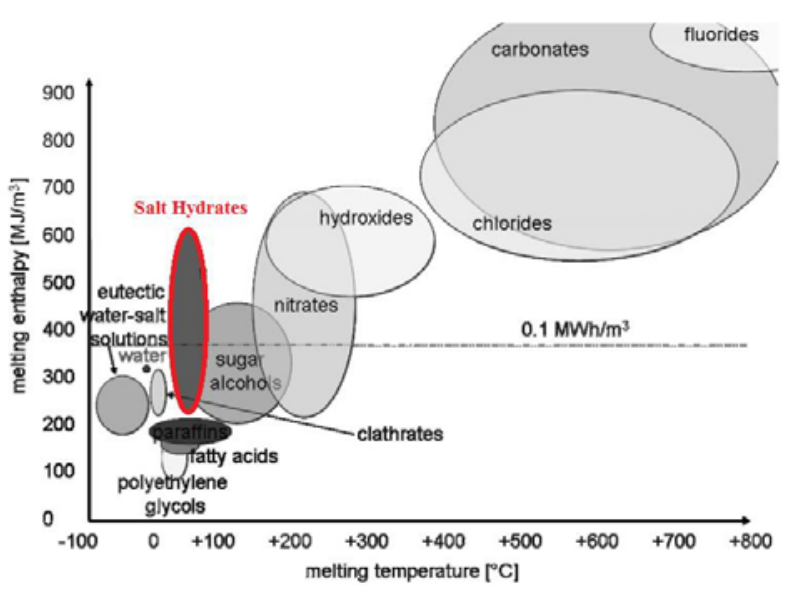

Figure 1 Types of PCM and their melting temperature [9]

Each of PCM has different physical properties. The PCMs used for transparent building elements are described in [5]. The authors [3] used a salt hydrate PCM inside the transparent window element. Calcium chloride hexahydrate was used as a PCM which was used in the window cavity in the polycarbonate container. Salt hydrates contain salts with a large and defined amount of crystal water. These materials are crystalline structures in which molecules of one type are enclosed in the crystal lattice of another $[1,9]$. Salt hydrates consist of two components water and salt, there can be a problem with phase separation. That problem is known as an incongruent melting. The incongruent melting is caused released water of crystallization process, salts are not able to dissolve all the phase present and due to density difference, the lower salts settles down at the bottom of a cavity [8].

Supercooling effect is a state when PCM do not solidify upon cooling below the melting temperature, but a PCM starts crystallization when the temperature of the

\footnotetext{
* Corresponding author: kolacek@,fai.utb.cz
} 
PCM which is well below the melting temperature is reached [9]. In the study [7], experimental results confirmed supercooling tendencies of calcium chloride hexahydrate $\left(\mathrm{CaCl}_{2.6} \mathrm{H}_{2} \mathrm{O}\right)$. Nevertheless, salt hydrates contain nucleating agents which improve nucleating properties and also increase the rate of crystal growth [4]. Nucleating agents can decrease supercooling effect from $20^{\circ} \mathrm{C}$ to $5^{\circ} \mathrm{C}$ as is described in [4]. Carbon nanofibers, cooper, titanium oxide, potassium sulfate and borax are appropriate nucleating agents as is shown in [12].

PCM as the transparent building envelope has been studied [3]. They used the PCM window panel which contained polycarbonate containers where the PCM was placed. Due to this technology, the PCM showed high thermal inertia and the temperature difference caused by the non-linear behavior of the PCM. New technology applies the PCM inside the whole space of the window cavity and improves thermal mass and ability of the PCM to store energy as declared by the producer. Nevertheless, the technology which placed the PCM inside the whole space of the window cavity can cause incongruent melting and formation of sediment.

In this article, we will be analyzed thermal inertia of the PCM window, crystallization process and also we will try to verify the possibilities of formation the sediment.

\section{Methods}

The measurement was performed on four-pane glazing system incorporating the PCM. Figure 2 shows the structure of four-pane window with a specific PCM. The prismatic glass is placed in the first window cavity. This element reflects high-angle solar radiation in summer and transmits low-angle in winter. The prismatic glass can control solar radiation over the whole year. The second cavity of the window contains Krypton gas and the third cavity contains the PCM. The PCM is Calcium chloride hexahydrate which is placed inside the whole space of the window cavity. This PCM has many properties similar to water, high latent heat and thermal conductivity equal to that of water $0,5 \mathrm{~W} / \mathrm{m}^{-1} \mathrm{~K}^{-1}$ in the liquid phase [4]. The melting point of the $\mathrm{PCM}$ is around $28^{\circ} \mathrm{C}$.

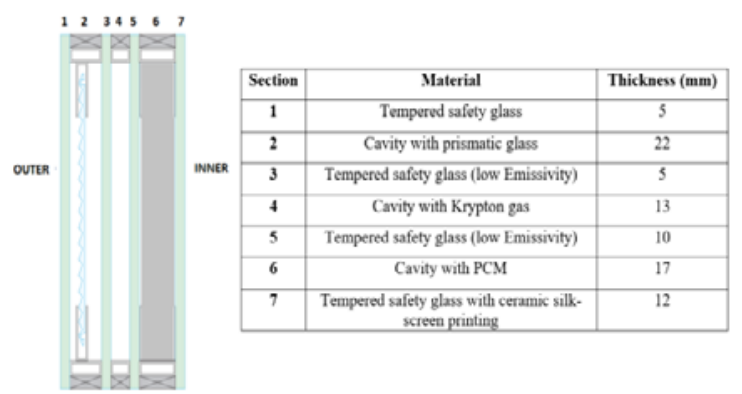

Figure 2 Structure of Four-pane building window with the PCM - Calcium chloride hexahydrate

\subsection{Instrumentation}

Temperatures were measured by thermocouples in four positions on each side of the window panel. Heat flows were measured on the both sides of the window. The thermal imager was used for the temperature stratification. It was important to cover the thermocouple from direct radiation. The aluminum shield covers all thermocouples.

In this work, measurements have been performed on the glazing system including the PCM using a climatic chamber. The climatic chamber is a device in which the climatic conditions on both sides of a glazing component can be dynamically controlled in the temperature range $-20^{\circ} \mathrm{C}$ to $+50^{\circ} \mathrm{C}$. The climatic chamber is made up of two chambers (indoor and outdoor) separated by the partition wall. Due to the fact that the chamber is compensated, we can control heat transfer only through the partition wall. The partition wall is $20 \mathrm{~cm}$ wide and the value of the thermal transmittance is $0,13 \mathrm{~W} \cdot \mathrm{m}^{-2} \cdot \mathrm{K}^{-1}$.

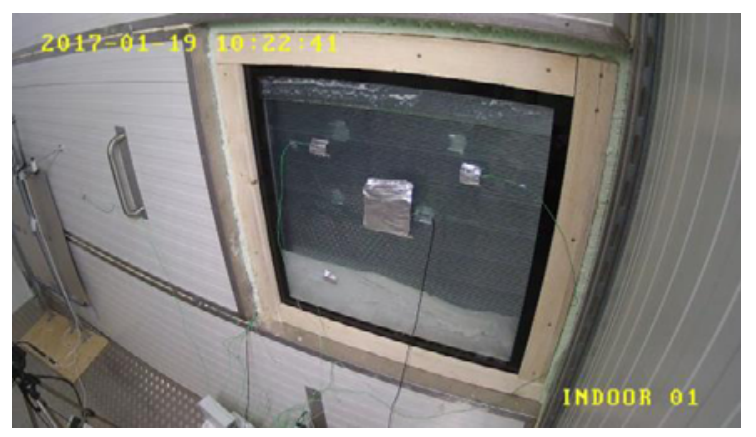

Figure 3 The PCM window panel placed in the partition wall of the calorimetric chamber

Figure 3 shows the window inside the calorimetric chamber where the window is installed in the partition wall.

\section{Results}

\subsection{Surface temperature measurement}

The measurement performed in three test series were carried out with the high air temperature in the outdoor chamber. Table 1 shows the climatic conditions of the calorimetric chamber, the duration of each cycle, the outdoor and indoor air temperature in the calorimetric chamber.

Table 1 Test cycle descriptions

\begin{tabular}{|c|c|c|c|}
\hline Test & $\begin{array}{c}\text { Outdoor air } \\
\text { temperature }\left[{ }^{\circ} \mathrm{C}\right]\end{array}$ & $\begin{array}{c}\text { Indoor air } \\
\text { temperature }\left[{ }^{\circ} \mathrm{C}\right]\end{array}$ & $\begin{array}{c}\text { Duration } \\
{[\text { hours }]}\end{array}$ \\
\hline 1 & 34 & 21 & 3 \\
\hline 2 & 34 & 21 & 8 \\
\hline 3 & 34 & 21 & 9 \\
\hline
\end{tabular}




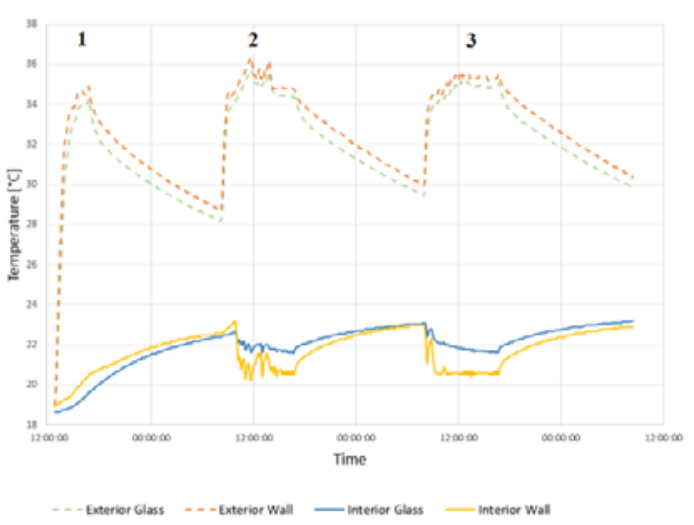

Figure 4 Surface temperature plots for test series. Exterior temperature was $34^{\circ} \mathrm{C}$ and interior temperature was $21^{\circ} \mathrm{C}$

As can be seen in Figure 4, the thermal inertia of the window is very high. Nevertheless, it was confirmed on the third cycle which took 9 hours. Thermal storage of the latent heat was activated when the PCM start melting. It is possible to verify that the Interior Glass temperature (blue curve) decreases lower than the temperature of Interior Wall (yellow curve). The latent heat of fusion of the PCM was activated. Nevertheless, the duration of the test cycle could be higher because the PCM did not melt all over.

\subsection{Heat radiation on the exterior surface}

The solar radiation cannot be applied in the climate simulator. However, it was applied the infrared heater which produces a maximum radiation level of $300 \mathrm{~W} / \mathrm{m}^{2}$. The heater was placed with the distance of the window sample of $20 \mathrm{~cm}$. The air gap reduced overheating of the exterior surface. The aim of this experiment was to simulate a high surface temperature on the exterior of the window.

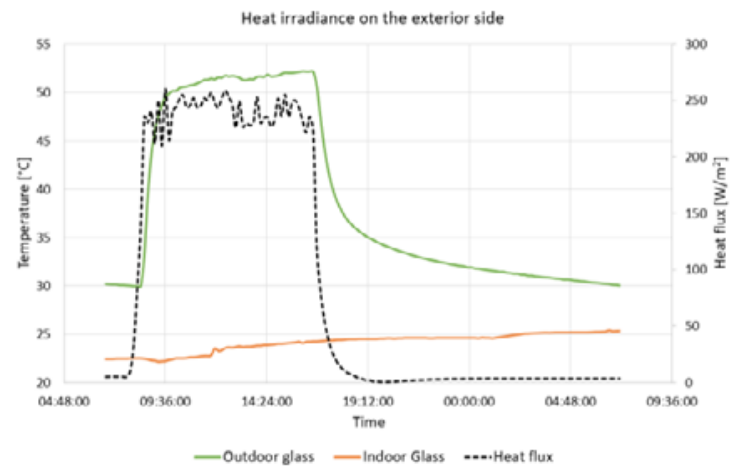

Figure 5 Measurement of heat radiation on the exterior side of the PCM window panel

Figure 5 shows the results of measurement the heat irradiance on the exterior side of the PCM window. The exterior surface temperature achieved $52^{\circ} \mathrm{C}$ and heat flow was $250 \mathrm{~W} / \mathrm{m}^{2}$ on the exterior side for 7 hours. When the infrared heater was turn off the surface temperature of exterior side decreased very slowly. The surface temperature on interior achieved only $25^{\circ} \mathrm{C}$. The experiment confirmed very high thermal inertia and also high storage capacity.

During testing infrared heater the PCM completely melted. After that, we evaluated thermal behavior of the PCM when the outside temperature decreased up to $-15^{\circ} \mathrm{C}$ in outdoor part of the climatic chamber. The melting process confirmed the formation of sediment that created at the bottom of the window cavity. The sediment and also the non-linear behavior of the PCM layer caused temperature differences on the surface of the window. It was important to measure the whole surface temperature of the window using a thermal imager. As can be seen in Figure 6, the 3D thermogram shows releasing of storage heat from the window. The air temperature was $-15^{\circ} \mathrm{C}$ in outdoor and the air temperature was $21^{\circ} \mathrm{C}$ in indoor, meanwhile, the surface temperature on the interior of the window was almost $25^{\circ} \mathrm{C}$.

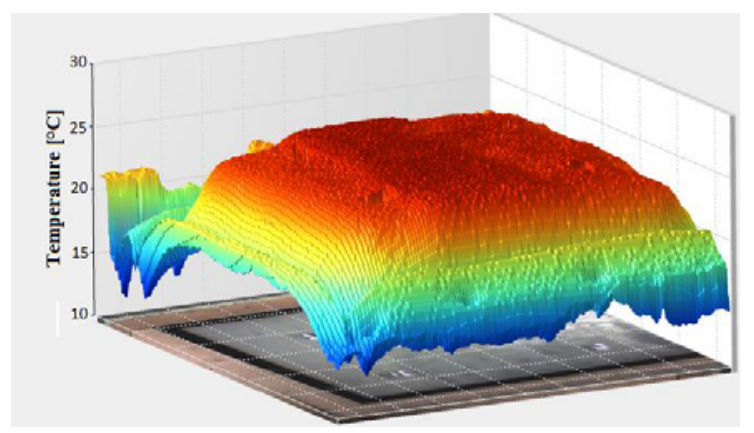

Figure 6 Thermogram of the PCM window panel during the crystallization process.

The crystallization process also confirmed supercooling tendencies of calcium chloride hexahydrate. The PCM started to crystalize when the temperature achieved $24^{\circ} \mathrm{C}$. However, the melting point of the $\mathrm{PCM}$ is $29^{\circ} \mathrm{C}$.

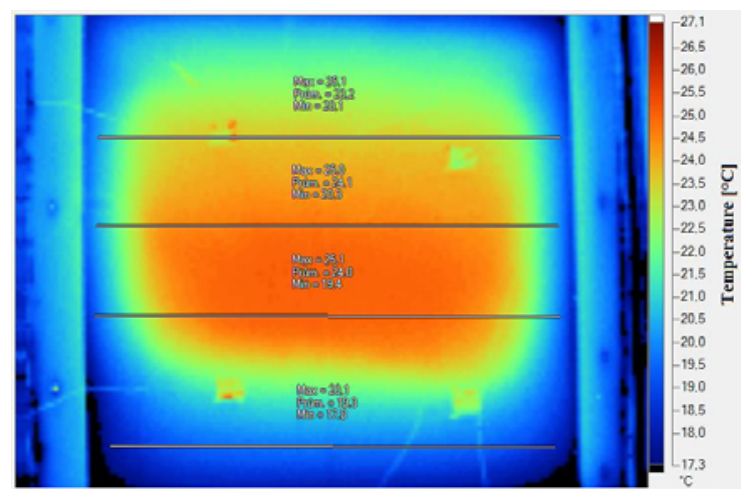

Figure 7 Thermogram and temperature stratification of the interior side of the window

Figure 7 shows the thermogram on the interior side during the crystallization process of the PCM. The storage energy released only in the area of the center of the window. The lower temperature was at the top of the window. Because there was an air gap that compensates for the pressure during the crystallization process of the PCM. However, the temperature was also lower at the bottom of the window. This was caused by the formation of sediment that was caused by incongruent melting of the salt hydrate. 


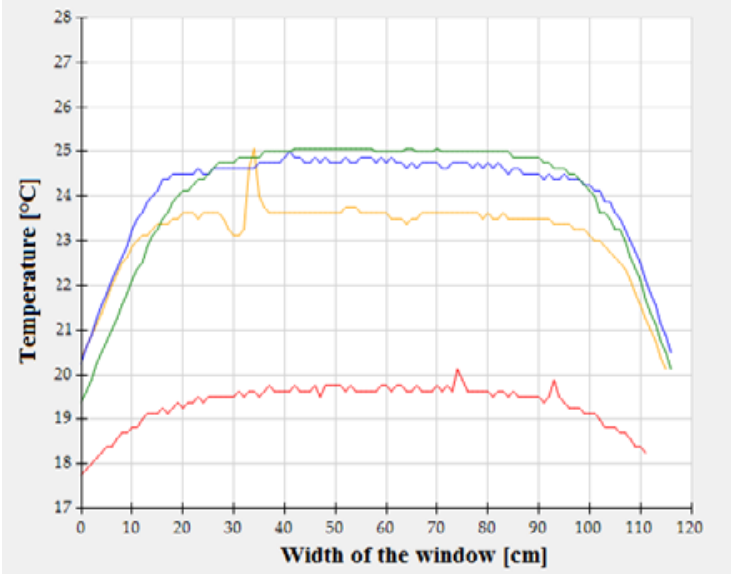

Figure 8 The temperature stratification of the thermogram in Figure 7

As can be seen in Figure 8, the temperature difference was $5^{\circ} \mathrm{C}$ between the sediment and the surrounding window area. The red curve represents the temperature on the sediment at the bottom of the window panel. These salts can not melt again enough and the sediment grows during repeated melting cycles. Calcium Chloride hexahydrate should be placed in a smaller volume where the incongruent melting would not occur.

The previous technology used the polycarbonate containers in which the PCM was placed. These containers improved the melting cycle of calcium chloride hexahydrate and the formation of sediment was minimized.

\section{Conclusion}

The aim of this paper has been to measure the thermal properties of the specific window panel which contained salt hydrates as a PCM. The window panel was tested with the high temperature of the exterior side. These tests were made at the different duration of each test. The infrared heater simulated high heat flow on the exterior side where it was evaluated melting process and subsequently crystallization process.

The limitation of this study is given by the infrared heater which was not used as a simulator of solar radiation but only to heat the exterior side. The results confirmed very high thermal inertia and also the high non-linear behavior of the PCM layer.

The continuation of this work will be to determine the thermal transmittance of the window panel and also it will be evaluated the window panel in the simulation module.

\section{Acknowledgments}

This work was supported by the Ministry of Education. Youth and Sports of the Czech Republic within the National Sustainability Programme project No.LO1303(MSMT7778/2014), by the European Regional Development Fund under the project CEBIA-Tech No.CZ.1.02/2.1.00/03.0089 and also by the Internal Grant Agency of Tomas Bata University in Zlín under the project No. IGA/CebiaTech/2017/002.

\section{References}

1. de Gracia, Alvaro and Luisa F. Cabeza. (2015). "Phase Change Materials and Thermal Energy Storage for Buildings." Energy and Buildings 103: 414-419.
2. Li, Shuhong, Gaofeng Sun, Kaikai Zou, and Xiaosong Zhang. (2016). "Experimental Research on the Dynamic Thermal Performance of a Novel Triple-Pane Building Window Filled with PCM." Sustainable Cities and Society 27: 15-22.

3. Grynning, Steinar, Francesco Goia, Egil Rognvik, and Berit Time. (2013). "Possibilities for Characterization of a PCM Window System using Large Scale Measurements. " International Journal of Sustainable Built Environment 2 (1): 56-64.

4. Fokaides, Paris A., Angeliki Kylili, and Soteris A. Kalogirou. (2015). "Phase Change Materials (PCMs) Integrated into Transparent Building Elements: A Review." Materials for Renewable and Sustainable Energy 4 (2).

5. Giovannini, Luigi, Francesco Goia, Verso, Valerio R M Lo, and Valentina Serra. (2017). "Phase Change Materials in Glazing: Implications on Light Distribution and Visual Comfort. Preliminary Results." Energy Procedia 111: 357-366.

6. Tyagi, V. V. and D. Buddhi. (2008). "Thermal Cycle Testing of Calcium Chloride Hexahydrate as a Possible PCM for Latent Heat Storage." Solar Energy Materials and Solar Cells 92 (8): 891-899

7. Taylor, Robert A., Naomi Tsafnat, and Alex Washer. (2016). "Experimental Characterisation of Sub-Cooling in Hydrated Salt Phase Change Materials." Applied Thermal Engineering 93: 935938.

8. Simon Furbo. Heat Storage with an Incongruently Melting Salt Hydrate as Storage Medium Based on the Extra Water Principle. (1980). Meddelelse Nr. 108. Technical university of Denmark.

9. Mehling, Harald and Luisa F. Cabeza. (2008). Heat and Cold Storage with PCM: An Up to Date Introduction into Basics and Applications. Berlin ; Heidelberg: Springer. ISBN :978-3-540-68556-2.

10. Gao, D., Deng T. (2013). "Energy storage: Preparations and physicochemical properties of solid-liquid Phase change materials for thermal energy storage“. Materials and processes for energy: communicating current research and technological developments. Energy Book Series 1. ISBN: 978-84-939843-7-3.

11. Garg H.P., Mullick S.C., Bhargava A.K. Solar thermal energy storage. D, Reidel Publishing Company. Dordrecht. Holland. (1985). ISBN13 :978-94-040-8841-1. DOI :10.1007 :978-94-0095301-7.

12. Chiu, Justin NingWei, Viktoria Martin, and Fredrik Setterwall. "A Review of Thermal Energy Storage Systems with Salt Hydrate Phase Change Materials for Comfort Cooling.". 11th International Conference on Thermal Energy Storage, Effstock, June 14-17, (2009), Stockholm, Sweden. 